\title{
Corrigendum to "Clinical Presentation, Natural History, and Therapeutic Approach in Patients with Solitary Fibrous Tumor: A Retrospective Analysis"
}

\author{
P. Schöffski iD, ${ }^{1,2}$ I. Timmermans, ${ }^{1}$ D. Hompes, ${ }^{3}$ M. Stas, ${ }^{3}$ Veerle Boecxstaens, ${ }^{3}$ F. Sinnaeve,${ }^{4}$ \\ P. De Leyn, ${ }^{5}$ W. Coosemans, ${ }^{5}$ D. Van Raemdonck, ${ }^{5}$ E. Hauben, ${ }^{6}$ R. Sciot $\mathbb{D}^{6},{ }^{6}$ P. Clement, ${ }^{1}$ \\ O. Bechter, ${ }^{1}$ B. Beuselinck, ${ }^{1}$ F. J. S. H. Woei-A-Jin, ${ }^{1}$ H. Dumez, ${ }^{1}$ P. Nafteux, ${ }^{5}$ \\ and T. Wessels $\mathbb{D D}^{1}$
}

${ }^{1}$ Department of General Medical Oncology, University Hospitals Leuven, Leuven Cancer Institute, Leuven, Belgium

${ }^{2}$ Laboratory of Experimental Oncology, Department of Oncology, KU Leuven, Leuven, Belgium

${ }^{3}$ Department of Surgical Oncology, University Hospitals Leuven, Leuven Cancer Institute, Leuven, Belgium

${ }^{4}$ Department of Orthopedic Surgery, University Hospitals Leuven, Leuven Cancer Institute, Leuven, Belgium

${ }^{5}$ Department of Thoracic Surgery, University Hospitals Leuven, Leuven Cancer Institute, Leuven, Belgium

${ }^{6}$ Department of Pathology, University Hospitals Leuven, Leuven Cancer Institute, Leuven, Belgium

Correspondence should be addressed to P. Schöffski; patrick.schoffski@uzleuven.be

Received 21 January 2021; Accepted 21 January 2021; Published 8 February 2021

Copyright (c) 2021 P. Schöffski et al. This is an open access article distributed under the Creative Commons Attribution License, which permits unrestricted use, distribution, and reproduction in any medium, provided the original work is properly cited.

In the article titled "Clinical Presentation, Natural History, and Therapeutic Approach in Patients with Solitary Fibrous Tumor: A Retrospective Analysis" [1], a co-author's name was missed in the author list. The corrected author list is as above.

\section{References}

[1] P. Schöffski, I. Timmermans, D. Hompes et al., "Clinical Presentation, Natural History, and Therapeutic Approach in Patients with Solitary Fibrous Tumor: A Retrospective Analysis," Sarcoma, vol. 2020, p. 9, Article ID 1385978, 2020. 